DOl: $10.1038 / \mathrm{s} 41467-017-02555-4 \quad$ OPEN

\title{
Publisher Correction: Broad modulus range nanomechanical mapping by magnetic-drive soft probes
}

Xianghe Meng ${ }^{1}$, Hao Zhang ${ }^{1}$, Jianmin Song ${ }^{1}$, Xinjian Fan ${ }^{1}$, Lining Sun ${ }^{1} \&$ Hui Xie ${ }^{1}$

Correction to: Nature Communications https://doi.org/10.1038/s41467-017-02032-y, published online 05 December 2017

In the original version of this Article, the text labels on the bottom-right panel in Fig. 1c were inadvertently displaced during the production process. The correct version is:

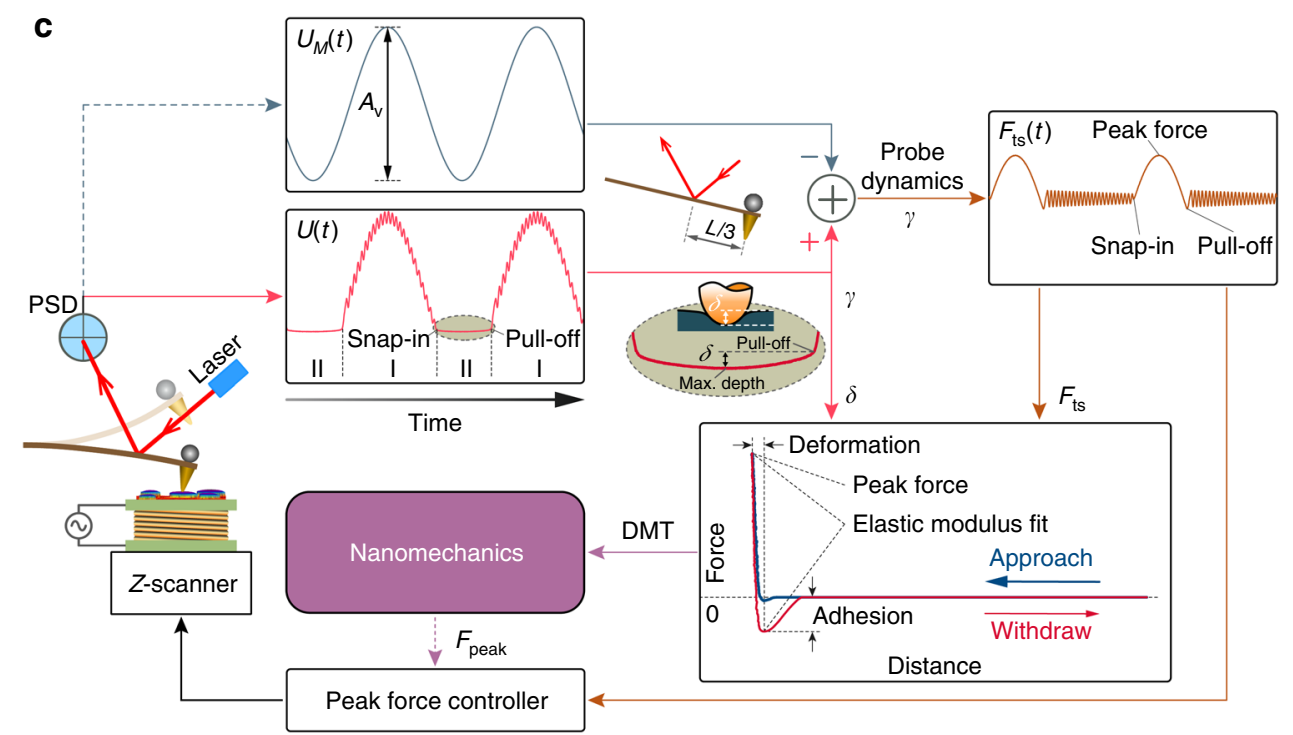

Fig. 1

which replaces the previous incorrect version :

\footnotetext{
${ }^{1}$ State Key Laboratory of Robotics and Systems, Harbin Institute of Technology, 2 Yikuang, Harbin, 150080, China. Correspondence and requests for materials should be addressed to H.X. (email: xiehui@hit.edu.cn)
} 


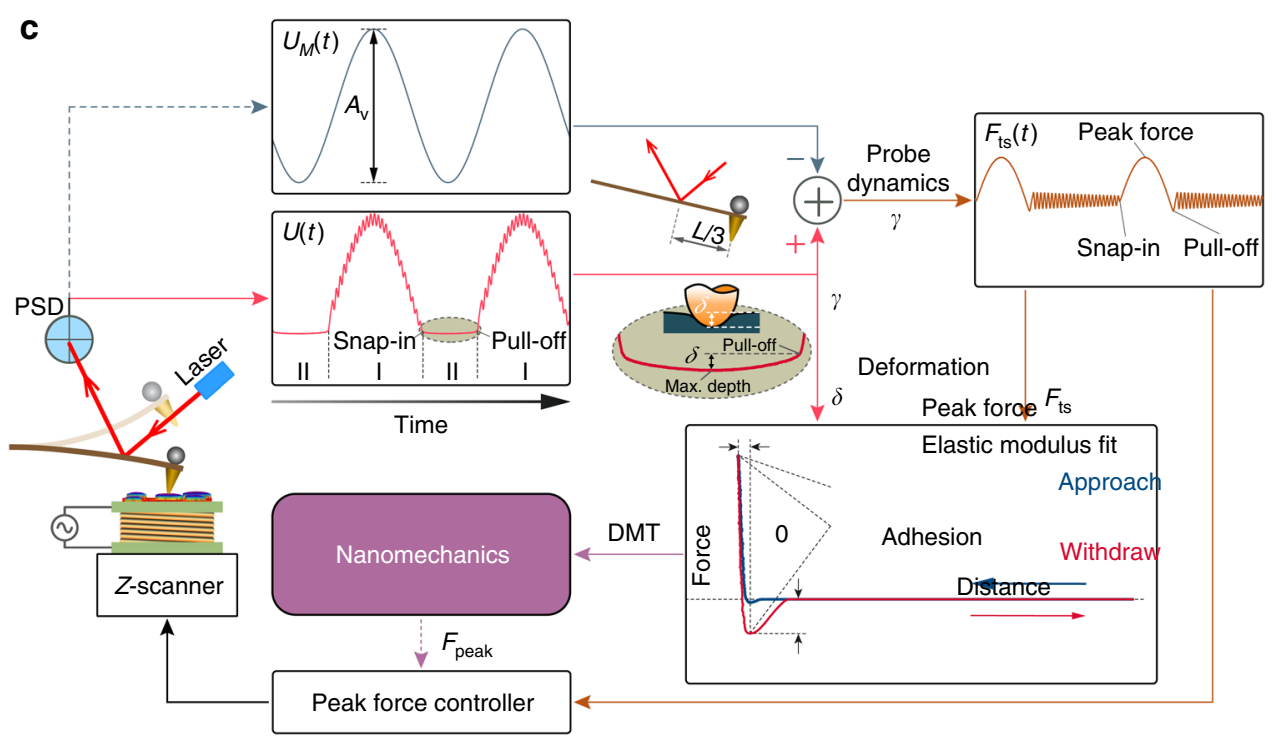

Fig. 2

This has now been corrected in both the PDF and HTML versions of the Article.

Published online: 16 January 2018

\begin{abstract}
(c) Open Access This article is licensed under a Creative Commons Attribution 4.0 International License, which permits use, sharing, adaptation, distribution and reproduction in any medium or format, as long as you give appropriate credit to the original author(s) and the source, provide a link to the Creative Commons license, and indicate if changes were made. The images or other third party material in this article are included in the article's Creative Commons license, unless indicated otherwise in a credit line to the material. If material is not included in the article's Creative Commons license and your intended use is not permitted by statutory regulation or exceeds the permitted use, you will need to obtain permission directly from the copyright holder. To view a copy of this license, visit http://creativecommons.org/licenses/by/4.0/.
\end{abstract}

(C) The Author(s) 2018 